\title{
New rules loom for US science funding as Congress passes a lean 1993 budget
}

\begin{abstract}
Washington. The end of the 102nd Congress last week also marks the end of a commitment to a steady growth in the federal funding of science. Next month's election of a US president and a new Congress promises to usher in an era in which research must demonstrate its relevance to society or to an important constituency to win favour with politicians. A close review is under way of a 45-year compact between the government and the academic community that assumes the value of basic research, and the elimination next year of artificial
\end{abstract} barriers on federal spending promises to intensify competition for scarce funds.

The news for 1993 is not good: the \$1.87-billion core research programme at the National Science Foundation (NSF) will receive $\$ 13$ million less than in 1992, for example, and the extramural research budget of the National Institutes of Health (NIH), some three times larger, will barely keep up with inflation. Space science within the National Aeronautics and Space Administration (NASA) is being squeezed to make room within a level budget for the continued construction of space station Freedom and a new advanced solid motor rocket. The Superconducting Super Collider, a presidential favour-

ite, was given only one-fifth of the $\$ 160$ million increase it requested, to $\$ 517 \mathrm{mil}$ lion, and the multi-billion-dollar budgets of initiatives that involve several agencies, including global climate change, science education and biotechnology, will be fortunate to stay at current levels.

No reputable analyst will even venture a guess about fiscal year 1994, which begins on 1 October 1993; there are simply too many uncertainties. Besides the results of the forthcoming election, there is much talk of renegotiating the terms of a 1990 budget agreement that would lift next year the limits on domestic discretionary spending (which includes all civilian research) and allow all programmes - military, civilian and international - to compete for the same amount of money, about $\$ 535$ billion, that was available in fiscal year 1993. How research would fare in that scramble is anybody's guess. Optimists see science carving out a slice of the military pie, while pessimists see it losing out in competition with jobs, housing, health care and other pressing domestic concerns.

Clearly, it is no longer enough for each agency to propose programmes that its constituents want and then hope that such proposals will be inserted into the budget. The fight is no longer, if it ever was, between 'big' and 'little' science, or between research and education, or even among disciplines. Bernadine Healy has spent much of her 18 months as NIH director trying to break the biomedical research community of its habit of defining success in terms of new R01 (individual investigator-initiated) grants because that goal is no longer enough to persuade Congress to increase the NIH budget. At NSF, director Walter Massey no longer mentions a presidential promise to

nevertheless, the outlines of this year's federal spending on science are beginning to emerge. Here are some highlights:

\section{National Science Foundation}

Although NSF officials expected 1993 to be a difficult year, it was still a shock that Congress refused the entire \$337-million increase they had requested for the six research directorates. (At the same time, Congress added $\$ 8$ million to a \$14-million requested increase for science education and appropriated $\$ 50$ million, $\$ 17$ million more than requested, for large instrumentation and rebuilding academic facilities.) Congress also said that $\$ 75$ million - nearly the full amount requested - must be spent this year on such costly new projects as the Laser Interferometer Gravitational Wave Observatory (LIGO), two 8-metre telescopes and a national high-magnetic field laboratory. The agency dislikes such 'earmarks' because it gives officials less flexibility in deciding which projects will be delayed or trimmed because of a lack of funds.

Language accompanying the spending bill ordered NSF to incorporate the recommendations of its Commission on the Future of NSF (see Nature 359, 261; 1992) into its operating plan for 1993

double the NSF budget within five years, first made in 1987, because he knows that it cuts no political ice.

Why is this? Massey tackled the question in surprisingly frank comments during a meeting last week of the National Science Board, which sets policy for the foundation. "It has become clear that there are major disagreements between our view of things and the view of Congress and the public", he stated. "The public hears that we're No.1 in science, and they want to know why that fact isn't making their lives better. The one thing that works in this country doesn't seem to be paying off, and I don't think that it's enough for us to say that we don't know why and that it's not our problem."

Without a crystal ball to forecast the economy, science policy-makers are left with reality, and they do not much like what they see: for the first time in recent memory, for example, Congress failed to match even the president's modest (an additional 4.5 per cent) request for NIH, and it flatly rejected a proposed 18 per cent increase for NSF's research programmes. The true impact of those meagre budgets will not register with the scientific community until each agency decides precisely how to spend its money; which must be submitted to Congress on 15 December. Although Congress toned down instructions in the Senate version of its appropriation that would have required it to pay more attention to applied research, the final language informs NSF that "it must change the fundamental emphasis it places on various research initiatives"; simply asking for more money for such programmes, it points out, is not the answer.

\section{National Institutes of Health}

The NIH budget will rise just three per cent, to $\$ 10.363$ billion, a figure that now includes the research components of the three institutes that made up the former Alcohol, Drug Abuse and Mental Health Administration, which merged with NIH in August. With biomedical research inflation somewhere between four and five per cent, NIH's 1993 budget looks like an effective cut, especially compared with last year's increase of nearly $\$ 1$ billion.

What this will mean to research grants is an open question. Unlike some previous funding bills, the 1993 budget does not include a specific target of 6,000 new and competing grants. It does, however, include a token $\$ 5$ million for laboratory improve- 
ment and construction at grant-receiving institutions, a new programme that is being welcomed by the research and university groups that have lobbied for years for $\mathrm{NIH}$ to address the problem of crumbling infrastructure at US universities.

In a related matter, Congress decided at the last minute to abandon temporarily a bill that would have offered an alternative to the current administration ban on fetal tissue research and established or modified several other NIH programmes, including those on the health of minorities and women. "We ran out of time, not votes", says Maureen Burns of the Association of American Universities.

\section{National Aeronautics and Space Administration}

As with NIH, the 1993 NASA budget will be essentially flat. But space science was treated relatively well. Big research projects such as the Earth Observing System, the Advanced X-Ray Astrophysics Facility and the Cassini mission to Saturn received about as much as the agency had requested, and space science received altogether an increase of slightly more than 4 per cent. Given that the overall NASA budget represents no growth at all - even for inflation - something had to give to make up for space science's rise. The obvious targets were those furthest away: Congress eliminated funding in 1993 for the planned National Aerospace Plane and for missions to the Moon and Mars. Although that action does not kill the two projects, it reduces the chances of success in fiscal year 1994.

For researchers who use satellite data, perhaps the most significant action as Congress moved towards adjournment was a major reform of the Landsat remote-sensing programme (see Nature 359, 353; 1992). The legislation will return Landsat to the government, ensuring a much-needed seventh orbiter and lower prices.

\section{Department of Energy}

Research spending by the Department of Energy (DOE) will grow hardly at all from 1992 levels. Funding for most programmes rose at most by one or two per cent, and some categories, including both high-energy and nuclear physics, suffered cuts. But Congress did provide the necessary sums for several physics projects under construction, including the Continuous Electron Beam Accelerator Facility (CEBAF) in Newport News, Virginia, the Relativistic Heavy Ion Collider (RHIC) at Brookhaven National Laboratories, and the Advanced Photon Source (APS) at Argonne National Laboratory. However, the Argonne project may yet fall victim to mandatory reductions to be negotiated between DOE and Congress during the next month that would delay by almost a year the opening, now scheduled for spring 1995, of some of its beam lines.

Christopher Anderson,

Jeffrey Mervis \& Traci Watson

\section{Human Frontiers looks for leader in Europe; US wavers}

Tokyo \& Munich. In a complex contest of science and politics, three leading scientists from Europe are vying to take charge of the Strasbourg secretariat of the Japaneseinspired Human Frontier Science Program (HFSP), which supports international research on the brain and biological functions. The situation will be further complicated if
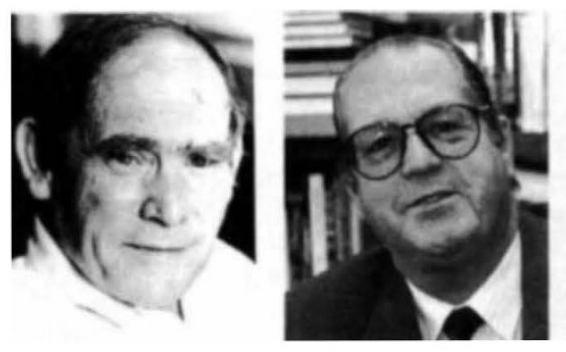

Sidney Brenner, Horst Sund and Michel Cuenod

the United States decides to nominate its own candidate.

The present secretary general, Sir James Gowans of Britain, will step down next spring following differences of opinion with Japanese and some European organizers of the programme over its direction (see $\mathrm{Na}$ ture 358, 527, 1992). So far, the three candidates for secretary general are Sydney Brenner, formerly at the Medical Research Centre and now at the University of Cambridge School of Medicine; Horst Sund of the University of Konstanz, Germany; and Michel Cuenod, director of the Brain Research Institute at the University of Zurich.

Any of the members of the programme (made up of Japan, the United States, Canada, the United Kingdom, France, Germany, Italy, Switzerland and the European Communi-

\section{User fees to hasten FDA review}

Washington. Drug companies will begin paying a fee to help the US Food and Drug Administration (FDA) to review new drug applications more quickly under legislation approved last week in the waning days of the 102 nd Congress. With the FDA's budget increasing by only 2.6 per cent this year. forcing companies to shoulder some of the financial burden is the only way that FDA can keep pace with its increasing workload. particularly in biotechnology.

The idea of charging users is not new: earlier this year, for example, the administration proposed raising $\$ 200$ million of the agency's \$791-million budget with such fees. The drug industry has traditionally opposed the idea, calling it a tax on innovation that would be particularly burdensome

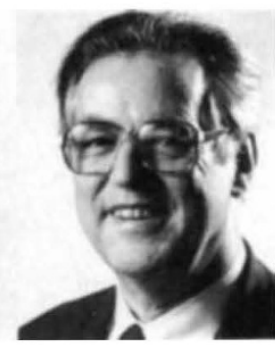

ties) may nominate a candidate. Although the official deadline for nominations was 15 September, Japanese government officials have indicated that late entrees will be accepted. The US candidate is Lawrence Bogorad of Harvard University. Bogorad has refused to comment, but knowledgeable sources in Washington confirm that his name is likely to be submitted once bureaucratic hurdles are cleared, perhaps as early as this week.

In an odd twist, Sydney Brenner was nominated not by Britain but by Italy. The United Kingdom did not nominate a candidate because of its displeasure with the treatment given to Gowans, whose name was put forward at the urging of Japan when the Frontiers organization was established in 1989. Japan did not nominate anyone to avoid appearing to dominate the programme.

The choice of secretary general will be made in Strasbourg next month by the HFSP board of trustees after the nominees have been screened by the HFSP council of scientists. The trustees must decide the extent to which he must be an expert in the fields supported by the programme and whether he should be a day-to-day administrator or more of an intellectual leader. Politics will also play a part: one country has already hinted that it will give more money to HFSP if its candidate is chosen. Japan now provides most of the funds for the nearly $\$ 40$ million programme.

David Swinbanks \& Alison Abbott

to new, small companies. But it acquiesced after Congress and the FDA agreed that the revenue would supplement - not replace - the agency's regular appropriation.

User fees are expected to bring in about $\$ 330$ million during the next five years, allowing the FDA to eliminate its backlog of new drug applications within two years and to shorten the average time of review from 24 to 12 months. To do this, the FDA would hire 600 new reviewers.

The bill takes into account the precarious financial status of small companies by permitting those with fewer than 500 employees and without products on the market to pay only half of the $\$ 100,000$ fee for a new drug application and to defer payment for one year.

Diane Gershon 